\title{
O diálogo da mediação: uma garantia de acesso à ordem jurídica humanizada
}

\section{The dialogue of mediation: a guarantee of access to the humanized legal order}

\author{
Clara Cardoso Machado Jaborandy ${ }^{I}$ \\ América Cardoso Barreto Lima Nejaim²
}

\begin{abstract}
RESUMO
O crescente aumento do número de ações judiciais e o descompasso em relação à concretização do acesso à justiça, através de uma prestação jurisdicional célere, eficiente e digna instigou a problematização desta pesquisa que consiste em verificar se a forma tradicional de composição de conflitos, representada por uma decisão judicial imposta, garante ao cidadão o acesso a uma ordem jurídica humanizada. Partindo deste problema foram investigados os aspectos sociológicos da mediação e seu papel na construção de uma sociedade consciente do sentido de justiça, com o intuito de romper com o aspecto meramente simbólico do acesso à justiça. Constatou-se a importância do incentivo à justiça coexistencial como forma de materializar a função social do processo e garantir o acesso à ordem jurídica humanizada. Por fim, sustentou-se a importância da mediação no restabelecimento do diálogo e na garantia de um tratamento do conflito. Para o desenvolvimento desse estudo, utilizou-se de pesquisa bibliográfica e documental, a partir do método dedutivo.
\end{abstract}

PALAVRAS-CHAVE:Acesso à justiça; Conflito; Mediação; Justiça Coexistencial.

\begin{abstract}
The large increase in the number of lawsuits and the lack of accountability in relation to the achievement of justice access, through a speedy, efficient and dignified judicial procedure, has instigated the problematization of this research, which consists in verifying that the traditional form of conflict composition, represented by a traditional judicial decision, guarantees the citizen access to a humanized legal order. Starting from this problem, were investigated the sociological aspects of mediation and its role in the construction of a society conscious of the sense of justice, with the intention of breaking with the merely symbolic aspect of the justice access. The importance of encouraging coexistential justice as a means of materializing the social function of the process and guaranteeing access to the humanized legal order was verified. Lastly, the importance of mediation in restoring dialogue and guaranteeing the treatment of conflict was sustained. For the development of this study, we used bibliographical and documentary research, based on the deductive method.
\end{abstract}

KEY WORDS: Access to justice; Conflict; Mediation; Coexistential Justice

\section{INTRODUÇÃO}

O relatório do Conselho Nacional de Justiça "Justiça em números 2017" registrou que o Poder Judiciário brasileiro finalizou o ano de 2016 com 79,7 milhões de

\footnotetext{
${ }^{1}$ Doutora em Direito pela Universidade Federal da Bahia. Mestre em Direito pela Universidade Federal da Bahia. Pós graduada em direito público pela Uniderp. Graduada em Direito pela Universidade Federal de Sergipe. Professora do Mestrado em Direitos Humanos da UNIT e de cursos de Graduação e pós graduação da UNIT.

${ }^{2}$ Mestre em Direito pela Universidade Estácio de Sá (2013). Atualmente é professora da Universidade Tiradentes (UNIT) e da Faculdade de Administração e Negócios de Sergipe FANESE.
} 
processos em tramitação. Somente no ano de 2016 deram entrada em 29,4 milhões de processos, retratando um crescimento de 5,6\% em relação a 2015 (CNJ, 2017).

Apesar da existência de norma orientadora ofertada pelo novo Código de Processo Civil incentivadora para a autocomposição do conflito, cuja legislação processual está em vigor desde março de 2016 não se observou ainda um aumento relevante de autocomposições de 2015 para 2016 que foi de apenas 0,8 ponto percentual (CNJ, 2017). A leitura deste relatório permite concluir que ainda há uma ausência de efetividade no acesso à ordem jurídica justa.

Sendo o acesso à justiça considerado um direito e ao mesmo tempo uma garantia constitucional que instrumentaliza e protege outros direitos fundamentais, faz gerar para o Estado o dever de assegurá-lo para toda a sociedade, por meio de mecanismos potencializadores da igualdade real para a sua concretização e, via de consequência, para se chegar à plenitude de se obter uma decisão justa dos conflitos sociais, com base no ideal de justiça social.

Diante dessa visão do acesso à justiça é que a Lei 13.105/2015, complementada pela Lei 13.140/2015 (Lei de Mediação), trouxe disposições processuais voltadas para o incentivo à justiça alcançada pelos meios consensuais de conflitos, sob a perspectiva da justiça coexistencial, pensada há tempos remotos pelo jurista italiano,Mauro Cappelletti.

Partindo dessa perspectiva, o legislador transformou os métodos autocompositivos em norma processual de caráter fundamental, incluindo a obrigatoriedade do Poder Judiciário, em cooperação com os advogados, defensores e promotores, de promoção e incentivo à política da solução consensual dos conflitos, como está exposto na redação do artigo $3^{\circ}, 3^{\circ}$, do CPC/2015.

Tal orientação normativa, desapegada da arcaica função automática da jurisdição estatal de solução do conflito pela justiça impositiva, vem trazer inovação social, inserindo a cultura da pacificação e o respeito à fraternidade, aqui compreendida como princípio jurídico que cria expectativas construtivas e possibilidades de espaços de diálogo em que, por meio da mediação de conflitos, são trabalhados e redefinidos os interesses comuns.

Para o desenvolvimento desse estudo, aplicou-se o método dedutivo já que partiu do princípio da fraternidade para compreender a importância do diálogo da mediação e assim verificar se por meio do diálogo há a garantia de uma ordem jurídica 
humanizada. Quanto à abordagem, foi utilizada a pesquisa qualitativa com revisão de bibliografia e análise de leis e decisões judiciais.

$\mathrm{O}$ artigo foi dividido em três partes. De início foram investigados os aspectos sociológicos da mediação e seu papel na construção de uma sociedade consciente do sentido de justiça, com o intuito de romper com o aspecto meramente simbólico do acesso à justiça. Após constatou-se a importância do incentivo à justiça coexistencial como forma de materializar a função social do processo e garantir o acesso à ordem jurídica humanizada. Por fim, sustentou-se a importância da mediação no restabelecimento do diálogo e na garantia de um tratamento sadio do conflito social.

\section{ASPECTOS SOCIOLÓCIGOS DA MEDIAÇÃO E SEU PAPEL ESSENCIAL NA CONSTRUÇÃO DE UMA SOCIEDADE CONSCIENTE DO SENTIDO DE JUSTIÇA.}

Junto com as constantes implementações de novos tipos de relações sociais vem a evolução do acesso à justiça que deve ser entendida como fenômeno social que está umbilicalmente ligado à busca dos ideais de justiça no tempo e no espaço através dos mais diversos tipos de conflitos, sempre com vistas a uma proteção dos direitos individuais e coletivos garantidos na Lei Maior.Esses diversos tipos de conflitos nascem de uma sociedade multicultural, onde cada grupo social busca a proteção de seus direitos fundamentais.

Com isso, a sociedade contemporânea vem a cada dia vivenciando uma notória crise do Poder Judiciário provocada pelo crescente número de ações judiciais propostas pelos cidadãos diante de conflitos das mais variadas espécies. Mas será que essa forma tradicional de composição de conflitos representada por uma decisão judicial vinda de uma análise da lei ao caso concreto garante ao cidadão o acesso a uma ordem jurídica justa em harmonia com os ideais filosóficos da justiça?

Portanto, para traçar linhas sobre o princípio do acesso à justiça como direito fundamental deve-se primeiramente considerar que ele se encontra presente e tutelado dentro de uma sociedade democrática, pautada na proteção à dignidade da pessoa humana, sendo considerado o requisito básico e essencial dos direitos humanos e 
garantia de um sistema jurídico igualitário, que visa proclamar e, acima de tudo, assegurar os direitos de toda a sociedade. (CAPPELLETTI, 1988).

Foi fazendo uma reflexão mais profunda sobre esses ideais de justiça, que Mauro Cappelletti, jurista italiano, fez emergir a importância da utilização dos meios alternativos de solução de conflitos, dentre eles, a mediação, como forma legal de democratização da distribuição da justiça, garantindo-se ao cidadão o seu direito ao acesso a uma ordem jurídica efetiva, oportuna, adequada e isonômica.

A concretização do verdadeiro conceito e sentido de acesso à Justiça, para atender às necessidades da sociedade contemporânea foi dada pelo aludido jurista italiano, onde no Projeto Florença fez uma percuciente e profícua pesquisa voltada para o acesso à justiça em inúmeros países do mundo, sendo publicado seu relatório no livro "Acesso à Justiça”, com parceria com Bryant Garth.

Nessa obra, o jurista faz um aparato sobre os obstáculos para a concretização do acesso à justiça representados pelo elevado valor das custas judiciais, pela desigualdade entre as possibilidades financeiras, pela desigualdade de capacidade jurídica das partes para reconhecer seus direitos, pelos problemas especiais dos interesses difusos referentes ao direito ao meio ambiente saudável e ao direito do consumidor. Assim, foram apresentadas soluções por meio da Teoria das Três Ondas Renovatórias.

Para o tema que está sendo abortado, traz-se a contribuição da terceira onda voltada para o novo enfoque dado ao acesso à justiça com a inclusão de advocacia judicial ou extrajudicial e a atenção ao conjunto geral de instituições e mecanismos, pessoas e procedimentos utilizados para processar e prevenir disputas nas sociedades modernas, concentrando as propostas de solução de solução de conflitos através de meios mais céleres e eficazes, dentre eles a conciliação e a mediação, como métodos de interferência apaziguadora para preservar os relacionamentos.

Foi trilhando esse caminho de busca para um amplo acesso à justiça, embalado pela terceira onda renovatória, que Cappelletti cria a noção de justiça consensual ou coexistencial, através de adoção de vias conciliatórias, onde as partes atuam de forma ativa, dando-lhe um enfoque diferenciado, mais apto para assegurá-lo, em contrapartida da justiça contenciosa. O citado autor assim afirma: "o Kampf ums Recht deve dar lugar ao Kampf um die Billigkeit, ou seja, à luta pela equidade, por uma solução justa e aceitável para todos os contendores". (CAPPELLETTI, 1994, p. 90) 
Percebe-se da sua exposição que o objetivo dessa justiça coexistencial é fazer com que a justiça alcançada seja a que realmente as partes do conflito almejam e ficam plenamente satisfeitas, diferente da justiça contenciosa imposta pelo Estado-Juiz, que nem sempre é a mais correta e adequada à realidade do conflito.

Com precisão, Fontainha (2009) afirma que a terceira onda proposta por Cappelletti pode ser representada pela expressão "desformalização das controvérsias", firmando a convicção de que a justiça não é alcançada somente através da jurisdição estatal.

Precursor dessa busca, Cappelletti deu ao acesso à justiça o sentido de concretização do ideal de justiça. Dentro desse nodal sentido, chega-se no emblemático ponto de análise do que venha ser considerada a expressão "justiça".

Para tanto, é importante trazer a esse estudo uma breve análise sobre os conceitos da expressão "justiça”, baseando-se no olhar filosófico de John Rawls, por meio da Teoria da Justiça, para que seja compreendido melhor o princípio do acesso à justiça, fazendo-se uma releitura diante da evolução constante dos direitos fundamentais do homem e suas perspectivas na sociedade hodierna.

Rawls, ao criar a Teoria da Justiça ${ }^{3}$, em 1971, procurou dar um enfoque à justiça como equidade, por meio de equilíbrio reflexivo sobre as questões políticas que envolvem os vários segmentos da sociedade, tendo como resultado da reflexão um consenso sobreposto.

O pensamento do filósofo americano ${ }^{4}$, com influência das ideias de Kant e Rousseau, centraliza-se na igualdade e na liberdade originárias dos cidadãos. Rawls (2003), deixa evidente em seus ensinamentos que para se ter a justiça como equidade, é preciso que a pessoa humana tenha uma concepção política e não metafísica, sendo considerada como um cidadão livre e em condições de igualdade com outro, trazendo dentro de si uma senso de justiça através de suas faculdades morais, podendo, dessa forma, haver cooperação entre as pessoas, base fundamental para se obter uma sociedade bem ordenada e, consequentemente, democrática, baseada nos princípios da justiça.

\footnotetext{
${ }^{3}$ A Teoria da Justiça marca o início do debate contemporâneo da justiça. (JEVEAUS, 2012)

${ }^{4}$ Senso de justiça de uma pessoa não é a que combina com suas opiniões emitidas antes que ela examine qualquer concepção de justiça, mas sim a que coordena os seus juízos em um equilíbrio refletido" (RAWLS, 1997, p.50)
} 
É dentro desse senso de justiça que se pode perceber uma valorização no direito fraterno, diante da necessidade de conscientização dos indivíduos do respeito ao direito do outro, agindo em cooperação para que haja igualdade na proteção dos direitos fundamentais com reciprocidade de comportamentos voltados para o verdadeiro ideal de justiça, não aquela imposta por um terceiro imparcial, mas aquela alcançada de forma efetiva pelos próprios protagonistas dos conflitos.

Essa leitura social e filosófica de justiça está pautada na necessária visão real dos indivíduos quanto às situações fáticas e jurídicas que os igualam e que os diferenciam, para uma distribuição igualitária dos valores sociais, permitindo somente uma distribuição desigual de um desses valores, se esse tratamento desequilibrado proporcionar uma situação de melhora para todos, em perfeita harmonia com a liberdade igual e a igualdade equitativa de oportunidades ${ }^{5}$. É o que Rawls denomina de "princípio da diferença", permitindo-se as desigualdades sociais e econômicas que visem ao benefício dos membros menos favoráveis da sociedade.

Portanto, consideram-se como pressupostos da Teoria da Justiça, a estrutura básica da sociedade (objeto primário da justiça), a cooperação entre as pessoas, num patamar de igualdade cidadã, a consciência do senso de justiça, e o equilíbrio reflexivo ${ }^{6}$, com vistas a se obter um consenso de ideais e direitos, sem que haja prevalência de um sobre o outro. É dentro desse olhar filosófico da justiça que se consegue enxergar a uma das funções do princípio da fraternidade, ou seja, a busca do equilíbrio entre liberdade e igualdade.

Resta demonstrado que pelo fato das pessoas estarem em bases de igualdade, possuindo os mesmos direitos podem, dentro da escolha dos princípios, convencer o outro de que existem razões viáveis para que seja acolhida a sua opção, diante do senso de justiça comum a todos, ajustando-se os pensamentos dos envolvidos dentro da coerência dos benefícios trazidos pelo consenso sobreposto.

Com a visão renovatória e humanística dada por Cappelletti ao princípio do acesso à justiça, questiona-se, então, qual o conceito real de justiça a ser trabalhado hodiernamente pelos operadores do Direito e vivenciado pelos cidadãos que buscam alcançá-la.

\footnotetext{
${ }^{5} \mathrm{~A}$ igualdade equitativa de oportunidades está representada pela possibilidade de se obter o maior benefício possível para os cidadãos que possuem menos privilégios dentro da sociedade. (RAWLS. 2000)

6 "É chamado de equilíbrio porque associa princípios com opiniões e é reflexivo porque permite saber quais princípios os julgamentos se conformam e conhecer as premissas das quais derivam"(RAWLS, 1997, p. 23).
} 
Porém, qual o significado de justiça para o Direito? Para a resposta a essa pergunta, busca-se âncoras na afirmativa de Otto Bachof, citado por Tartuce (2008) que, inspirado no pensamento rawlsiano, expõe que a existência de um consenso social constitui-se em pressuposto da ideia de justiça, apontando como postulados, o respeito e a proteção da vida humana e da dignidade da pessoa humana; a proibição da degradação do homem em objeto; o direito ao livre desenvolvimento da personalidade; a exigência da igualdade de tratamento e a proibição do arbítrio.

Entretanto, considerar a lei como único delimitador do conceito de justiça não é o suficiente para se alcançar o seu verdadeiro sentido, precisando do auxílio axiológico fornecido pela filosofia.

Portanto, para fundamentar a ampliação do alcance do princípio do acesso à justiça, é preciso buscar o sentido holístico da justiça, permitindo-se e validando a justiça privatizada prestada fora dos limites da jurisdição estatal, até mesmo como um meio de evitar a utilização da máquina judiciária, quando os conflitos de interesses podem ser resolvidos por meio de um diálogo consciente entre as partes.

Nessa senda, Rodrigues (1994) preleciona que devem ser dados dois sentidos ao acesso à justiça: um, colocando-o como sinônimo de "justiça", ou seja, como sinônimo de "poder", prescindindo essencialmente de acesso ao Poder Judiciário e; outro; como escala de valores e direitos fundamentais que vão além da justiça contenciosa.

Enveredando por esse mesmo aforismo, Wolkmer (2006) chama a atenção no sentido de que a finalidade precípua do direito em qualquer lugar não está voltada para resolução do conflito, mas no sentido de criar uma pacificação da ordem interna existente nas relações sociais. Tem-se, desse modo, que mentalizar o direito dentro desse norte, estará aproximando-o do sentido axiológico e holístico da justiça, já que não será fruto de uma imposição estatal, mas um caminho cônscio escolhido pelas partes do conflito, fincando a paz social.

Além dessa visão filosófica da justiça, deve-se ter em mente a função sociológica da mediação.

Esse método de solução do conflito tem como técnica a conscientização dos impactos dos litígios para as partes, papel esse realizado pelo mediador, sendo essa a sua primeira função perante os conflitantes.

Para se alcançar esse ideal de justiça, surge a necessidade de se aplicar uma conscientização entre os indivíduos e o próprio Estado, quanto ao respeito recíproco na 
utilização e na defesa dos direitos que são inerentes a cada um, por meio de diálogos, facilitadores da existência da tolerância e respeito mútuos, como forma de pacificação social, inclusive, de caráter preventivo no sentido de evitar os conflitos sociais de qualquer natureza.

Com isso, tem-se que a mediação é instrumento adequado para a composição de conflitos familiares, ambientais, trabalhistas,educacionais e coletivos, para trazer uma cultura de diálogo, conscientizadora dos direitos fundamentais envolvidos nos litígios e o respeito recíproco que deve existir entre os participantes desse cenário.

Com a mediação há o incentivo das partes do litígio a fazerem uma reflexão profunda sobre os direitos fundamentais que estão em jogo, fazendo com que elas fiquem desnudas dos sentimentos que impedem um olhar de reciprocidade dos direitos, da consciência dos limites que cada um deve respeitar para não violar os direitos sociais de liberdade, segurança, bem-estar, igualdade, solidariedade, que se constituem em verdadeiros valores de uma sociedade pluralista, para que, dessa forma, se possa realmente viver em harmonia.

É mergulhando nessa conscientização recíproca do reconhecimento da dignidade da pessoa humana, que vem à tonao princípio da fraternidade, gerando a responsabilidade dos indivíduos na participação democrática da vida social.

\section{INCENTIVO À JUSTIÇA COEXISTENCIAL}

A nova visão de justiça coexistencial trazida pela Lei Processual Civil vem reforçar os valores contidos na Lei Maior, presentes em seu preâmbulo, dentre eles destaca-se a fraternidade, com vistas a uma convivência social solidária, com atributos de respeito e tolerância entre todos os indivíduos, cujos valores são verdadeiras inspirações para as interpretações a serem realizadas pelo aplicador do Direito no exercício da sua função jurisdicional.

Houve, notoriamente, uma verdadeira mudança de paradigma, tendo em vista que o legislador coloca como prioridade uma atuação ferrenha do Julgador com vistas a uma composição amigável dos conflitos que lhes são apresentados via propositura de ação judicial. 
Tal finalidade altruísta de solução de conflito está expressa na redação do artigo $3^{\circ}, \S \S 2^{\circ}$ e $3^{\circ}$, aliada ao que está previsto nos artigos $139, \mathrm{~V}, 565,694,932$, I, todos do $\mathrm{CPC} / 2015$.

Importante ressaltar que essa política de incentivo à utilização dos métodos consensuais de conflitos pode ser utilizada a qualquer tempo no processo, ou seja, em grau de recurso, após publicação do acórdão ou até mesmo na tutela executiva, conforme análises dos processualistas civis brasileiros fulcradas nos enunciados $371^{7} \mathrm{e}$ $485^{8}$, do FPPC, e até mesmo dentro entendimento do STJ, como se observa no Informativo 572 da terceira turma ${ }^{9}$.

Essa nova cultura de pacificação social do conflito faz com que o julgador conscientize a sociedade da importância de se buscar uma solução amigável e fraterna,para se evitar uma solução por meio de uma decisão judicial imposta pelo Estado às partes do conflito.

Destarte, esses mecanismos alternativos proporcionam ao jurisdicionado a concessão de uma prestação jurisdicional mais célere e eficaz, com a obtenção de um resultado útil e suficiente, dando-se efetividade ao processo $^{10}$, como também de propostas de humanização do acesso à justiça.

A importância que o legislador quis dar à prioridade para a solução amigável do conflito que colocou como norma imperativa, a obrigatoriedade, dentro do rito

\footnotetext{
${ }^{7}$ Enunciado 371, FPPC. Os métodos de solução consensual de conflitos devem ser estimulados também nas instâncias recursais.

${ }^{8}$ Enunciado 485, FPPC. É cabível conciliação ou mediação no processo de execução, no cumprimento de sentença e na liquidação de sentença, em que será admissível a apresentação de plano de cumprimento da prestação.

${ }^{9}$ Informativo 572, Terceira Turma do STJ - DIREITO PROCESSUAL CIVIL. TRANSAÇÃO JUDICIAL APÓS PUBLICAÇÃO DO ACÓRDÃO. A publicação do acórdão que decide a lide não impede que as partes transacionem o objeto do litígio. A tentativa de conciliação dos interesses em conflito é obrigação de todos os operadores do direito desde a fase pré-processual até a fase de cumprimento de sentença. Nesse passo, o Código de Ética e Disciplina da OAB, no art. $2^{\circ}$, parágrafo único, VI, prevê, dentre os deveres do advogado, "estimular a conciliação entre os litigantes, prevenindo, sempre que possível, a instauração de litígios". No mesmo sentido, são inúmeros os dispositivos legais que preconizam a prática da conciliação, no curso do processo, com o objetivo de pôr termo ao litígio (arts. 277, 448 e 794, II, do CPC, dentre outros). De mais a mais, ao magistrado foi atribuída expressamente, pela reforma processual de 1994 (Lei 8.952), a incumbência de tentar, a qualquer tempo, conciliar as partes, com a inclusão do inciso IV ao artigo 125 do CPC. Com efeito, essa medida atende ao interesse do Estado na rápida solução dos litígios e converge para o ideal de concretização da pacificação social. Logo, não há marco final para implementá-la. REsp 1.267.525-DF, Rel. Min. Ricardo Villas Bôas Cueva, julgado em 20/10/2015, DJe 29/10/2015 (Informativo 572).

${ }^{10}$ Bedaque $(2009$, p.75) afirma que a ideia da efetividade processual constitui-se uma garantia fundamental retirada dos princípios constitucionais, base do ordenamento jurídico brasileiro, dispondo que o "acesso à ordem jurídica justa significa o acesso de todos à via constitucional de solução de litígios, livres de qualquer óbice que possa comprometer a eficácia do resultado, pretendido por aquele cujos interesses estejam amparados no plano substancia.
} 
comum, de realização de audiência preliminar de mediação e de conciliação. É importante frisar que tão forte é essa imperatividade normativa que a audiência preliminar somente ficará dispensada para os casos cujo direito em litígio não admite a autocomposição ou quando ambas as partes manifestarem expressamente desinteresse na realização dessa audiência. Perceptível, portanto, que não basta a manifestação apenas do autor no desinteresse da realização da audiência apresentada no bojo da petição inicial, devendo o juiz aguardar a manifestação expressa do réu, dentro do prazo de 10 dias antes da realização da audiência, nesse mesmo sentido. Essa é a inteligência da redação presente no caput do artigo 334 e $\S \S 4^{\circ}$ e $5^{\circ}$, do CPC.

E por que ser obrigatória a designação da audiência de mediação/conciliação ainda que o autor expresse na sua petição inicial o seu desinteresse? Justamente para que, por meio das técnicas específicas utilizadas pelos mediadores/conciliadores, seja realizada uma conscientização do respeito recíproco dos direitos fundamentais de ambas as partes, do limite do exercício de cada um, para que por meio do diálogo seja alcançada a composição através do reconhecimento mútuo das partes. Tem-se, então, caracterizada a base da função social do processo.

Uma vez designada a audiência, torna-se dever das partes o comparecimento, cuja ausência injustificada irá se constituir em ato atentatório à dignidade da justiça penalizado com uma multa no valor de até $2 \%$ sobre o valor da vantagem econômica pretendida ou do valor causa, nos termos do artigo $334, \S 8^{\circ}$, do CPC.

Mas não é só no rito comum que se observa a imposição da designação da audiência preliminar de mediação ou de conciliação. Tal obrigatoriedade também é sentida nas ações litigiosas de família, como reza a redação dos artigos 694 e 695, do CPC, bem como nos litígios possessórios coletivos de força velha, não podendo ser concedida liminar possessória antes da realização da audiência de mediação, como prevê o artigo 565, do mesmo diploma legal.

Vislumbra-se, dessa forma, que o intuito do legislador foi afastar a tradicional cultura bélica de solução do conflito como prioridade na solução dos conflitos, mas colocando-se no campo da subsidiariedade, ou seja, a primeira tentativa de solução será pela via da autocomposição, somente utilizando do processo como justiça impositiva em caso do não êxito nas inúmeras tentativas de finalização amigável do processo. É dentro dessa nova perspectiva que o Poder Judiciário poderá dar uma prestação jurisdicional mais célere, justa, oportuna e adequada. 
Contudo, para que esse objetivo do legislador seja alcançado é preciso que exista uma imediata conscientização da sociedade e dos operadores do direito sobre esse novo olhar processual, por meio de palestras, inserção dessa cultura do diálogo nas escolas e faculdades, além da necessidade de serem realizadas políticas públicas na implantação de centros de mediação e de conciliação adequados, compostos de mediadores e conciliadores qualificados para a efetivação dessas técnicas eficazes de solução de conflitos. A inércia dos três poderes quanto a tais pontos, é tornar letra morta à norma fundamental processual insculpida no artigo $3^{\circ}, \S \S 2^{\circ} \mathrm{e} 3^{\circ}$, do $\mathrm{CPC}$ e na Lei de Mediação.

Destarte, deve haver o verdadeiro aprendizado sobre o valor do diálogo para o alcance da justiça no seu sentido mais puro, cujo conhecimento e conscientização sobre essa forma de solução de conflito deve ser transferida de geração em geração.

Aliado ao princípio do incentivo à justiça coexistencial está o princípio da função social do processo, caminhando de mãos dadas para o alcance da verdadeira justiça conscientizada e fraterna.

O princípio da fraternidade tem como elemento estruturador a dignidade humana e tem, essencialmente, três funções: função de equilíbrio entre liberdade e igualdade, função de reconhecimento e função interpretativa. Destaca-se, nesse momento, a função de reconhecimento da fraternidade que explicita a alteridade e a intersubjetividade no direito, impondo-se do sujeito de direito um olhar para o outro, o respeito às diversidades numa sociedade multicultural (processo de inclusão), o espírito de tolerância, de compreensão mútua e de solidariedade (MACHADO, 2017). O princípio da fraternidade aplicado ao processo relaciona-se com sua função social no exercício da prestação jurisdicional.

Esse princípio constitui-se num enfoque mais moderno que deve ser dado ao objetivo do processo, deixando de ser uma visão meramente jurídica, ou seja, de mero instrumento de aplicação do direito material, para ser uma visão de concretização da justiça, em estreita harmonia com o preâmbulo da constituição quando refere à construção de uma sociedade fraterna, bem com uma integração do ordenamento jurídico, em que o julgador irá aplicar a norma jurídica com vistas aos fins sociais e ao bem comum, como previsto no art. $5^{\circ}$, da LICC e no artigo $8^{\circ}$, do CPC.

Segundo leciona Dinamarco (2004), a função social do processo é formada pelo binômio pacificação social e educação. No primeiro caso, o processo está voltado 
para pacificar com justiça os conflitos entre as pessoas e; no segundo caso, o processo deve servir para educar os participantes do processo a agirem na defesa dos próprios interesses, respeitando os direitos alheios.

Assim, o juiz deverá, dentro de sua imparcialidade, aproximar-se mais das partes, conhecer o contexto social e econômico da demanda, interpretando de forma profunda o conflito que lhe foi apresentado para sua decisão final seja justa, tanto sob a ótica jurídica quanto sob a ótica social.

O juiz deve além de ter o compromisso com a Lei, ter compromisso com a Justiça, fazendo com que o processo não se torne um mero instrumento de observância literal das formalidades, mas sim um meio para se alcançar a verdade real e solucionar o conflito da forma mais eficaz para ambas as partes, que deverão estar conscientizadas reciprocamente dos direitos fundamentais inerentes a cada um.

Essa função social que o processo civil moderno transforma em norma expressa no artigo $8^{\circ 11}$, torna a fraternidade como norma de conduta a ser observada pelos indivíduos e pelo Estado, ao ter o dever de promover a dignidade da pessoa humana no momento da aplicação da norma jurídica, como direciona o supracitado dispositivo legal.

\section{A FUNÇÃO DA MEDIAÇÃO NO RESTABELECIMENTO DO DIÁLOGO - UMA VISÃO CONSCIENTE E FRATERNA}

Mediar diz respeito ao compartilhamento das responsabilidades, simbolizando um processo de integração entre as pessoas e grupos sociais, cuja finalidade, na percepção de Fabiana Marion Spengler (2010, p. 312) é "reabrir os canais de comunicação interrompidos e reconstruir laços sociais destruídos”. Para o alcance deste objetivo, as partes devem reconhecer as diferenças e ressignificar o conflito a fim de restabelecer a comunicação ${ }^{12}$.

\footnotetext{
${ }^{11}$ Art. $8^{\circ}$, CPC. Ao aplicar o ordenamento jurídico, o juiz atenderá aos fins sociais e às exigências do bem comum, resguardando e promovendo a dignidade da pessoa humana e observando a proporcionalidade, a razoabilidade, a legalidade, a publicidade e a eficiência.

${ }^{12}$ Utilizando mais uma vez os ensinamentos de Fabiana Marion Spengler (2010, p. 231) “a mediação, como ética da alteridade, reivindica a recuperação do respeito e do reconhecimento da integridade e da totalidade dos espaços de privacidade do outro, repudiando o mínimo de movimento invasor e dominador.
} 
Apesar de na mediação a solução do conflito ser alcançada pelas próprias partes, não resta dúvida que esta somente se concretiza por causa da função essencial do mediador, que possui o papel de restabelecer a comunicação entre as partes quando houver obstáculos à efetivação da solução do conflito.

Para Targa (2004), o mediador é:

[...] aquele que facilita o processo de entendimento, controlando a conversa e auxiliando as partes a vislumbrar pontos de inserção em seus interesses, que podem ser importantes para a elaboração de um acordo e, principalmente, para a efetivação de um acordo e, principalmente, para a efetivação de um futuro relacionamento, mais agradável.

A função do mediador, portanto, não é apresentar soluções, já que essas devem ser buscadas pelas próprias partes, mas sim restaurar a comunicação entre elas, apaziguando os ânimos acirrados, orientando o caminho mais tranquilo para a discussão do conflito, dando oportunidade para que todos exponham seus fatos, suas dores, seus descontentamentos, suas insatisfações, mas sempre sabendo respeitar os sentimentos do outro, refletindo e questionando qual a melhor solução para que os interesses conflitantes possam encontrar um denominador comum, que satisfaça a todos.

Para se conseguir essa tarefa árdua de restabelecer uma comunicação sadia entre os conflitantes, é preciso que o mediador ganhe a confiança das partes, para que elas possam expor todos seus argumentos e que esses sejam recepcionados de forma positiva pela outra parte, atuando como fio condutor, unindo as partes para a efetivação do diálogo progressivo para atingir a almejada solução do conflito.

Assim, o mediador ao possuir uma função de administrar conflitos, precisa ter capacidade, habilidade técnica e atributos subjetivos, ou seja, perfil, para que seu exercício de mediar ocorra de forma regular e eficiente. Não sendo, dessa forma, uma atividade exercida por qualquer pessoa, mas por um indivíduo que se identifique com a figura de um mediador, na plenitude de sua essência.

Para Santos (2012), os atributos subjetivos do mediador estão baseados em características específicas como: imparcialidade, colocando-se numa posição equidistante e sem interesse no resultado; saber ouvir de forma ativa os conflitantes, para proporcionar acolhimento e confiança; capacidade de percepção das complementares, e o Direito como solidariedade". 
particularidades dos mediados e do conflito, como interesses, fragilidades, possibilidades; diligência e criatividade, para proporcionar que as partes criem soluções para manter a igualdade no resultado do conflito; clareza e objetividade na comunicação verbal e escrita, para que sua linguagem seja entendida pelos mediados e que o acordo transpareça fielmente a vontade das partes; flexibilidade ou capacidade de adaptação de suas técnicas, para saber lidar com os diversos rumos que o conflito pode tomar; estabilidade emocional e paciência, para saber lidar com o tempo de cada um e a dinâmica específica de cada negociação; empatia, para proporcionar aos mediados confiança em sua pessoa e, por fim; organização, para presidir a sessão de mediação.

Possuindo tais características subjetivas, o mediador deve ter uma atuação de investigador do conflito, buscando informações sobre o problema que envolve as partes, ou seja, quais as causas que provocaram o conflito e quais as suas consequências, fazendo com que as partes percebem que precisam enfrentar o problema e elas mesmas encontrem a solução que as satisfaçam de forma plena e igualitária (solução do ganhaganha), conscientizadas da reciprocidade dos direitos fundamentais de ambas.

Para que realmente as partes enfrentem o problema, o mediador deve fazer com que haja a sua emersão, fazendo com que as partes se deparem com ele de frente, da maneira mais transparente possível, buscando resolver todos os impasses existentes, para que o conflito passe pelo processo de alquimia, atingindo a sua plena pacificação, não restando quaisquer resquícios de conflito entre elas.

Portanto, jamais o mediador poderá apresentar soluções, dizendo o que deve ser feito, ainda que seja instigado pelos mediados, mas apenas agir como facilitador da comunicação entre eles, restabelecendo os vínculos anteriormente existentes, provocando uma mudança de atitudes que proporcionará às partes chegarem à sua própria solução comum do conflito.

Agindo dessa forma, o mediador estará exercendo fielmente sua função de colaborador para a concretização do acordo, onde através de técnicas específicas irá incentivar as partes a alcançarem uma solução voluntária, conjunta e não-adversarial, função esta que será desenvolvida do início ao fim do processo de mediação.

Além de tais atributos subjetivos, o mediador deve estar sempre preparado para auxiliar as partes a encontrarem uma solução viável. Para tanto, faz-se imprescindível que o mediador passe por um processo sério e comprometido de capacitação, através de 
cursos de formação onde serão ensinadas as técnicas que são de suma importância para o cumprimento de seu papel de facilitador da comunicação entre os mediados.

Com isso, têm-se como funções primárias do mediador: presidir as sessões da mediação, colocando em pauta o conflito; ouvir os participantes da mediação para descobrir os seus reais interesses e necessidades; interpretar o conflito para conhecer a fundo sua causa e seus efeitos; utilizar técnicas para facilitar a comunicação entre os mediados para que participem da negociação de forma colaborativa; ser realista com as partes orientando-as a não formularem propostas de acordos inviáveis e inexequíveis, fático e juridicamente e; preocupar-se com o desequilíbrio extremado e notório entre os mediados (SANTOS, 2012).

No que se refere ao procedimento da mediação este se divide em duas fases: a pré-mediação, com o encaminhamento dos interessados ao mediador, realizando uma entrevista com as partes para realizar o diagnóstico da situação e a contratação dos serviços; e a fase da própria mediação, onde ocorrerá a tentativa de formalização do acordo (TARTUCE, 2008).

Antes de adentrar de forma mais percuciente nessas duas fases do processo de mediação, faz-se mister registrar que ele possui uma característica específica que se diferencia do processo judicial. Na mediação, deve haver organização dos atos, com início, meio e fim, porém o mediador deverá estar sempre preparado para a imprevisão e desvincular-se de padrões pré-estabelecidos, pois as especificidades de cada caso apresentado determinarão o andamento do procedimento, as técnicas que serão utilizadas, a quantidade de sessões e o tempo de cada uma (SANTOS, 2012).

Portanto, todo processo de mediação deve ter preparação, que se constitui na primeira fase da mediação; desenvolvimento e encerramento, onde essas duas últimas etapas formam a segunda fase da mediação.

A preparação ou sessão de pré-mediação constitui-se na fase preliminar de um atendimento de mediação. Compreende a reunião dos profissionais (advogados, psicólogos, mediador) com o objetivo de esclarecer as finalidades da mediação e as suas benesses para o impasse, bem como a atribuição e papel de cada um envolvido no processo de mediação. Será a fase do acolhimento dos indivíduos interessados na mediação, onde o mediador fará sua autoapresentação e apresentação da parte que procurou a utilização da mediação, para que exponha o motivo que a levou, permitindo que o mediador identifique as primeiras informações do conflito, como causas e efeitos, 
e qual a situação que se encontra o diálogo entre as partes (ativo, fragilizado ou inexistente). Dentro dessa fase, o mediador não deve utilizar palavras ou frases negativas, para evitar que conflito seja potencializado (SANTOS, 2012) ${ }^{13}$.

Feitos tais esclarecimentos, parte-se para uma entrevista com os envolvidos no conflito que pode ser, primeiramente, individual, depois conjunta, com o intuito de diagnosticar as causas e o nível que o conflito se apresenta. Deste modo, tem como objetivo buscar em primeiro plano afastar a litigiosidade, buscar o espírito de cooperação e o respeito recíproco entre as partes, apontando a responsabilidade que cada envolvido possui na obtenção da solução do conflito (TARTUCE, 2008).

Após essa fase de apresentações pessoais, passa-se para o momento em que o mediador irá explicar os objetivos da mediação e como ocorre seu funcionamento através de um discurso que irá abrir a sessão da pré-mediação, em que serão esclarecidos pontos importantes como os princípios da mediação e as suas vantagens.

Realizada essa função de conscientização da importância da mediação e do restabelecimento do diálogo entre as partes, parte-se para a segunda fase que está voltada para o procedimento efetivo da mediação, em que será feita a abertura da sessão, com o esclarecimento das regras, devendo haver a manutenção dos compromissos provisórios e permanentes de tentativas conciliatórias até a finalização do procedimento de mediação.

Nesta fase, também será delimitado o conflito, através das exposições feitas pelas partes, momento em que será feita uma apuração dos fatos que provocaram o conflito, sendo ofertada aos mediados uma oportunidade de reflexão e questionamento, colocando-se um no lugar do outro, fazendo-se os resgatar o respeito ao direito inerente a todos, demonstrando os benefícios que terão em se alcançar uma solução que será adequada, justa, efetiva para ambos, em que todos sairão ganhando. (TARTUCE, 2008)

Na sessão de mediação, deverá desde o início ficar definida a ordem de fala dos mediados e, no decorrer do procedimento, o mediador deverá sempre estar atento para realizar o controle das reações negativas das partes e qualquer intervenção inoportuna. Ressalte-se que em qualquer sessão de mediação, o mediador deve proporcionar a existência de uma interação comunicativa, onde as partes deverão estar acompanhadas de advogados ou defensores públicos.

\footnotetext{
${ }^{13}$ Como exemplos de palavras contra indicadas para o mediador: problema, culpa, dolo e responsável. Exemplos de frases contra indicadas: "Você tem mesmo toda razão", "Discordo de você", "Se eu tivesse no lugar dele, me sentiria...", "Não faria isso se eu estivesse na sua situação" (SANTOS, 2012, p. 243)
} 
Dentro dessa integração comunicativa, muito se tem utilizado a teoria do agir comunicativo, ditada por Habermas (1997). Seguindo este pensamento habermasiano, a comunicação na sociedade é de fundamental importância para que se chegue no auge da justiça e da democracia,em que a validade da norma é medida pela razão argumentativa que melhor convença o ouvinte a aceitar o seu conteúdo.

É baseada nesta teoria do agir comunicativo que emerge a importância da mediação como meio alternativo de solução de conflitos sociais, já que a ação comunicativa é orientada para o acordo, para o entendimento mútuo que leva a um consenso. Diante disto tem-se a importância dessa ação no sistema da mediação, no qual há a utilização de um diálogo participativo e ativo, cuja solução do conflito nasce da construção de alternativas propostas pelos próprios envolvidos.

A teoria do agir comunicativo de Habermas é aplicada inteiramente na mediação funcionando como meio eficaz e célere para as soluções dos conflitos sociais, já que os envolvidos possuem uma participação com diálogos, expondo seu ponto de vista, seu entendimento, argumentando e contra-argumentando até se chegar a um denominador comum, construído juntos, atingindo não só uma solução, mas a melhor solução para o caso em análise.

Prevalece, assim, na mediação, acima de tudo, o respeito ao princípio da fraternidade na dimensão do reconhecimento do outro, dada pela oportunidade das partes de se comunicarem, exporem seus pensamentos, seus sentimentos e suas opiniões, participando ativamente no processo de construção da solução ideal para o conflito, sem que haja a intervenção e imposição de um terceiro, já que o papel essencial do mediador é de auxiliar as partes envolvidas, proporcionando um diálogo entre elas, sem opinar e sem interferir, sendo sempre imparcial, buscando apenas afastar os obstáculos que impedem a composição do litígio. Esse papel do mediador é apontado expressamente no artigo $165, \S 3^{\circ}$, do CPC.

Partindo da concepção de Habermas (1997), a facilidade na solução dos conflitos está na maior capacidade dos envolvidos de se comunicarem, compreenderemse através de uma comunicação dialógica, racional e participativa, deixando de lado a razão individual e se apegando à razão comunicativa e plural, por meio de uma integração de discursos, para conferir validade à norma pela melhor argumentação, dos cidadãos que atuam de forma isonômica, para alcançar a justiça efetiva. 
Estabelecida a comunicação entre as partes do conflito e expostas todas as considerações pelas partes, chega-se ao final da sessão de mediação, com a obtenção ou não do acordo. Sendo esse obtido, será elaborado o termo de acordo "dentro dos limites dos interesses, da razoabilidade e das necessidades de cada um dos envolvidos". (SANTOS, 2012, P. 176), sendo, ao final homologado pelo Poder Judiciário, valendo a respectivo termo como título executivo judicial, nos termos do artigo 515, II e III, do CPC.

Explicitado todo o procedimento da mediação, conclui-se que diante de sua flexibilidade, adequando-se as técnicas para cada caso concreto específico apresentado para o mediador, essa forma alternativa de conflito constitui-se num meio eficaz na composição do conflito, diante da reaproximação das partes através do diálogo, tratando a controvérsia e alcançando uma solução satisfatória para todos, contribuindo, dessa forma, para a pacificação social, com o alcance do equilíbrio entre liberdade e igualdade, bem como a conscientização das partes quanto aos direitos fundamentais pertencentes a cada uma.

\section{CONSIDERAÇÕES FINAIS}

As mudanças normativas no processo trouxeram uma inversão de valores quanto à primordial função da jurisdição, ressaltando a necessidade de ser afastada a cultura adversarial para a solução dos conflitos, para se aproximar de um alcance da justiça social por meio da cultura da pacificação consensual, através de um diálogo consciente das partes envolvidas, havendo um reconhecimento mútuo no campo dos direitos fundamentais, atingindo-se o equilíbrio entre a liberdade e a igualdade de todos.

É através dessa visão do direito, pautada no princípio da fraternidade, que se alcança uma justiça harmônica e isonômica entre as partes, por meios de atos de reconhecimento e respeito em verdadeira contemplação dos direitos e deveres fundamentais.

Nesse jaez, tem-se que quando o Poder Judiciário preza pela via prioritária da autocomposição do conflito estará, sem sombras de dúvidas, promovendo o princípio da fraternidade que tem como núcleo a dignidade humana, norma orientadora prevista no 
artigo $8^{\circ}$, do CPC que visa reeducar a sociedade na busca da inclusão dos indivíduos nos diversos tipos de relação jurídica, trazendo para si e para os participantes do conflito, a responsabilidade recíproca na participação democrática da vida social.

Esse caminho a ser traçado pelo Estado, utilizando-se da fraternidade na solução do conflito faz com que exista a responsabilidade dos indivíduos quanto ao exercício dos direitos fundamentais pelo outro, por meio de sua função de reconhecimento. Essa necessidade de tornar a função jurisdicional mais fraterna, solidária e igualitária surge a partir da diversidade cultural que impera na sociedade hodierna, influenciada pelas constantes evoluções de pensamento do homem e dos seus valores éticos e sociais.

A mediação, que invoca a política saudável do diálogo, procura deixar de escanteio uma visão egocêntrica do direito, em que através de uma função sensibilizadora do respeito recíproco dos direitos fundamentais, faz com que exista uma nova filosofia de vida entre todos os indivíduos, que estarão mais conscientes de que agindo com fraternidade, conseguirão uma maior efetivação do seu direito a uma vida digna.

A implementação profunda da mediação no seio de toda a sociedade, inclusive, através de diálogos entre grupos sociais, agindo como fomentadora da fraternidade, gera o bem comum e a paz social.

É através do agir comunicativo por meio do diálogo, que a mediação garante a efetividade dos direitos fundamentais, trazendo o reconhecimento recíproco da dignidade humana, passando o direito a exercer sua função social, tendo a fraternidade como uma norma de conduta a ser seguida pelos indivíduos e pelo próprio Estado.

\section{REFERÊNCIAS BIBLIOGRÁFICAS}

ANDRADE, José Carlos Vieira de. Os direitos fundamentais na Constituição portuguesa de 1976. $3^{\mathrm{a}}$ ed. Coimbra: Almedina, 2007, P. 46.

BEDAQUE, José Roberto dos Santos. Tutela cautelar e tutela antecipada: tutelas sumárias e de urgência (tentativa de sistematização). 5. ed. São Paulo: Malheiros, 2009.

BOBBIO, Norberto. Da estrutura à função: novos estudos de teoria do direito. Trad. Daniela Becaccia Versiani. Baueri: Manole, 2004

CAPPELLETTI, Mauro. Acesso à Justiça. Editora Sergio Antonio Fabris Editor. Porto Alegre. 1988. 
. Os métodos alternativos de solução de conflitos no quadro do

movimento universal de acesso à justiça. São Paulo. Ano 19 n. 74, p. 82-97, abr-jun. 1994.

. Problemas de Reforma do Processo nas Sociedades Contemporâneas,

Revista Forense n. 318 pp. 119/128.

COUTINHO, Sérgio. A Recepção Como Pragmática Argumentativa - uma visita ao conceito pelo olhar habermasiano. In Perspectiva Teológica n. 37. 2005.

DINAMARCO, Cândido Rangel. Instituições de Direito Processual Civil. Vol. I, p 128, $4^{\mathrm{a}}$ Ed. Malheiros, São Paulo, 2004.

FERRAZ JR., Tércio Sampaio. Teoria da norma jurídica: ensaio de pragmática da comunicação normativa. 4 ed. Rio de Janeiro: Forense, 2006.

FONTAINHA, Fernando de Castro. Acesso à Justiça: da contribuição de Mauro Cappelletti à realidade brasileira. Editora Lumen Juris. Rio de Janeiro 2009.

FREIRE, Fernanda Ayoub de Luna. Métodos alternativos de resolução de controvérsias: aspectos gerais. Disponível em http://www.emerj.tjrj.jus.br/paginas/trabalhos_conclusao/1semestre2012/trabalhos_120 12/fernandaayoubfreire.pdf. 2012. Acesso em 04 ab 2018.

GHISLENI, Ana Carolina; SPENGLER, Fabiana Marion. Mediação de conflitos a partir do Direito Fraterno. Santa Cruz do Sul: EDUNISC, 2011.

HABERMAS, Jürgen. Direito e democracia: entre facticidade e validade. Rio de Janeiro. Tempo Brasileiro, 1997, t. I.

JEVEAUX, Geovany Cardoso (Org.). Uma Teoria para o Acesso à Justiça.In Uma Teoria da Justiça para o acesso à justiça. Editora GZ. Rio de Janeiro. 2012.

MACHADO, Clara. O princípio jurídico da fraternidade. Rio de Janeiro: Lumen Juris, 2017.

RAWLS, John. Justiça como Equidade: uma reformulação. São Paulo, Martins Fontes, 2003.

. Uma Teoria da Justiça. Tradução Almiro Piserra e Lenita M. R. Esteves. São Paulo. Martins Fontes. 1997. . Justiça e Democracia. São Paulo, Martins Fontes, 1998.

RODRIGUES JÚNIOR, Walsir Edson. A prática da mediação e o acesso à justiça. Belo Horizonte: Del Rey, 2006.

SANDEL, MICHAEL. JUSTIÇA, O que é fazer a coisa certa. Rio de Janeiro. Editora Civilização Brasileira. 2011. 
SANTOS, Ricardo Goretti. Manual de Mediação. Rio de Janeiro. Editora Lumen Juris. 2012.

SARMENTO, Daniel. O Neoconstitucionalismo no Brasil: Riscos e Possibilidades. In FELLET, André Luiz Fernandes; PAULA, Daniel Giotti de; NOVELINO, Marcelo (Org.) As Novas Faces do Ativismo Judicial. Salvador. Jus Podivm. 2011.

SILVA NETO, Manoel Jorge e. Proteção Constitucional dos interesses trabalhistas: difusos, coletivos e individuais homogêneos.São Paulo, LTr, 2001, p. 16.

Curso de Direito Constitucional.8 ed. São Paulo: Saraiva, 2013, p.168.

SPENGLER, Fabiana Marion. Da jurisdição à Mediação: por uma outra cultura no tratamento de conflitos. Ijuí: Ed. Unijuí, 2010.

TARTUCE, Fernanda. Mediação nos Conflitos Civis. São Paulo. Editora Método. 2008.

WARAT, Luis Alberto. Em nome do acordo: a mediação no direito. Argentina: Almed, 1998.

WOLKMER, Antonio Carlos. Síntese de uma história das ideias jurídicas: da antiguidade à modernidade. Florianópolis: Fundação Boiteux, 2006.

Submetido em: $21 / 04 / 2018$

Aceito em: 18/05/2018 